\title{
Neuroprotective Effects of Sildenafil on Traumatic Brain Injury in an Experimental Rat Model
}

\author{
Serdar Ercan ${ }^{1}$ Ayfer Aktaş \\ ${ }^{1}$ Department of Neurosurgery, Eskisehir City Hospital, Eskisehir, \\ Turkey \\ 2Dicle University, Medical Faculty, Department of Histology and \\ Embryology, Diyarbakir, Diyarbakir, Turkey \\ Indian J Neurotrauma 2022;19:100-104.
}

\begin{abstract}
Address for correspondence Serdar Ercan, MD, Department of Neurosurgery, Eskisehir City Hospital, 71 Evler mahallesi, Odunpazari Eskisehir, Turkey (e-mail: srdrercn@gmail.com).
\end{abstract}

\begin{abstract}
Keywords

- Sildenafil

- brain injury

- trauma

- experimental

- neuroprotection

- secondary damage

Objective Not only primary injuries, secondary injuries such as posttraumatic biochemical cascades, ischemia, and hypoxia also affect the morbidity and mortality of traumatic brain injury (TBI). Sildenafil released the vasodilatation by relaxing the smooth muscle of the systemic artery and vein. Also, the effects of sildenafil are evidenced in multiple sclerosis, Alzheimer's disease, and memory loss as a part of experimental studies. Sildenafil decreases oxidative stress by increasing the cGMP level. We aimed to examine the protective effects of sildenafil on TBI with histopathological and biochemical parameters.

Methods 21 Sprague-Dawley rats were separated into three groups $(n=7)$. "The weight drop injury model," which was described by Marmou, was used for the head injury. Group 1: nontraumatic sham group, Group 2: nontreated TBI group, Group 3: sildenafil $(100 \mathrm{mg} / \mathrm{kg})$ treated TBI group. The whole brain and serum were collected for histopathological and biochemical study. The histopathological sections were examined under a light microscope.

Results On comparison of total antioxidant status (TAS), total oxidant status (TOS), nitric oxide (NO), and plasma nitrite/nitrate (PNOx) between groups, NO level was significantly high in group $3(p=0.013)$. Even though the TAS level was significantly high in group $3(p=0.02)$, there were no significant differences in TOS level in groups $(p=0.225)$. Disappearing Nissle granules occurred in a pyknotic situation in the cell nucleus, and acidophilic staining in neuron cells, which describe the neuron degeneration observed in the trauma group. The neuron degeneration markers were not seen in the sildenafil-treated trauma group.

Conclusion Our study has shown that sildenafil decreases the oxygen radicals and affects the recovery of experimental TBI in rats.
\end{abstract}

\section{Introduction}

Head injury is one of the most important health problems that kill, cripple, and require long-term treatment and care. In modern populations, developing technologies and social

published online

February 18, 2021
DOI https://doi.org/

10.1055/s-0041-1724148

ISSN 0973-0508. life increase TBI incidence and mortality and morbidity risk factors. It especially affects young adults, with loss of production, and acute and chronic treatment costs lead to severe economic losses. ${ }^{1,2}$ When examined carefully, it was determined that not only severe head trauma but mild and

(C) 2021. Neurotrauma Society of India.

This is an open access article published by Thieme under the terms of the Creative Commons Attribution-NonDerivative-NonCommercial-License, permitting copying and reproduction so long as the original work is given appropriate credit. Contents may not be used for commercial purposes, or adapted, remixed, transformed or built upon. (https://creativecommons.org/licenses/by-nc-nd/4.0/).

Thieme Medical and Scientific Publishers Pvt. Ltd. A-12, 2nd Floor, Sector 2, Noida-201301 UP, India 
moderate head trauma also cause permanent disability. ${ }^{3}$ In the United States, 235,000 people are hospitalized every year, 1.1 million people are treated as outpatients in the emergency department, and approximately 50000 people die. ${ }^{1,4}$

TBI is classified as primary and secondary injury. Although neurodegeneration in head trauma occurs due to primary mechanical movement (nerve cells, vascular structure, shaking, rupture, etc.), it is important to deal with the secondary damage that occurs after the primary damage and the occurrence of pathochemical and pathophysiological cascades that affect the actual prognosis. ${ }^{5-8}$ The level of lactic acid increases, and adenosine triphosphate (ATP) and phosphatase decrease at the early periods of TBI. In other words, primary ischemia begins in the early period of TBI. This progressive tissue ischemia is the main cause of secondary tissue destruction. Ischemia needs to be delayed if recovery from head trauma is desired. ${ }^{9}$

The most important secondary damage shown by experimental studies is the oxidative destruction of lipid, protein, and nucleic acids caused by free oxygen radicals. ${ }^{10}$ The brain has less tolerance for oxygen deficiency and oxidative stress than other organs. Therefore, the brain must be protected against oxygen radical-induced trauma and ischemia. ${ }^{10}$

Sildenafil was produced in 1998 and used for the treatment of erectile dysfunction. It makes vasodilatation by relaxing the smooth muscle of systemic arterial and venous vessels. ${ }^{11,12}$ As a result of this effect, it has been shown experimentally that it is useful in some clinical conditions such as multiple sclerosis, Alzheimer's, and memory losses, as used in the treatment of diseases such as erectile dysfunction and pulmonary hypertension. ${ }^{13,14}$

In this study, we aimed to investigate whether sildenafil inhibits the effect of tissue hypoperfusion in patients with a head injury; thus, preventing secondary destruction.

\section{Materials and Methods}

Twenty-one Sprague-Dawley rats (250-300 gr) were housed in an airconditioned room with 12 hours light and dark cycles, where the temperature $\left(23 \pm 2^{\circ} \mathrm{C}\right)$ and relative humidity (65-70\%) were kept constant. All experimental protocols were approved by the Medicine Animal Care and Use Committee of the local university.

Rats were separated randomly into three experimental groups ( $n=7)$. Group I: nontraumatic control group, Group 2: nontreatment after TBI, and Group 3: treated with sildenafil (100 mg/kg) after TBI. ${ }^{16,20}$. Sildenafil was dissolved in ethanol/serum physiologic $(1: 1)$ and administered by the intraperitoneal way.

All rats were in normal motor functions. Anesthesia was induced by intramuscular injections of ketamine $(60 \mathrm{mg} /$ $\mathrm{kg}$ ) and xylazine $(9 \mathrm{mg} / \mathrm{kg})$. Animals were allowed to breathe spontaneously. The core temperature was monitored with a rectal probe. "The weight drop injury model," which was described by Marmou, was used for the formation of head injury. ${ }^{15}$

The rats were sacrificed after 24 hours by cardiac blood extraction. The blood was centrifugated, and the plasmas were frozen at $-80^{\circ} \mathrm{C}$ in the freezer. Total antioxidant status (TAS), total oxidant status (TOS), nitric oxide (NO), and plasma nitrite/nitrate (PNOx) were examined from plasma by the same biochemist who was blind to the groups. Brain tissue was removed and fixed with formaldehyde $10 \%$. Twenty-four hours later, the tissues were dehydrated in routine alcohol series $(70,80,90,96,100 \%)$ and embedded in paraffin. Five-mm sections from paraffin blocks were constituted and stained with hematoxylin and eosin (H\&E). The sections were examined by the same pathologist who did not know the groups. Brain edema was evaluated by the drying-weighing method. ${ }^{33}$ The whole brain was weighed and then dried for 48 hours at $100^{\circ} \mathrm{C}$; afterward, it was reweighed. The percentage of water was calculated according to the following formula: $\% \mathrm{H} 2 \mathrm{O}=([$ wet weight-dry weight $] /$ wet weight $) \times 100$.

Mann-Whitney U test was used to analyze the difference between groups. SPSS program was used for statistical tests.

\section{Results}

The mortality rate was $1 / 7$ (14\%) in group 2 and group 3 . Deaths occurred in the first minutes after the induction of trauma in group 2, and 24 hours later in group 3. The edema was evaluated by the drying-weighing method, and the water content of the brain was significantly increased in the trauma group when compared with the sildenafil-treated trauma group $(p=0.01 ;-$ Fig. 1$)$. The results of NO level in plasma were significantly increased in the sildenafil group when compared with the trauma group (26.8 $\pm 2, p=0.001$; - Fig. 2$)$. In groups 1 and 3 , the results showed that sildenafil was significantly increased the NO level $(p=0.002)$. The results of the TAS level were significantly increased in the sildenafil group when compared with the trauma group $(1.57 \pm 0.2, p=0.02 ;$ - Fig. 3$)$. There was no significant difference in TOS levels between groups 2 and 3 (17.79 $\pm 3, p=0.225$; - Fig. 4). Similarly, there was a statistically significant increase in PNOx values between groups in comparison with TAS. $(115.73 \pm 12, p=0.338$;

\section{-Fig. 5)}

Morphological examination revealed normal histological structure in brain tissues taken from the sham group

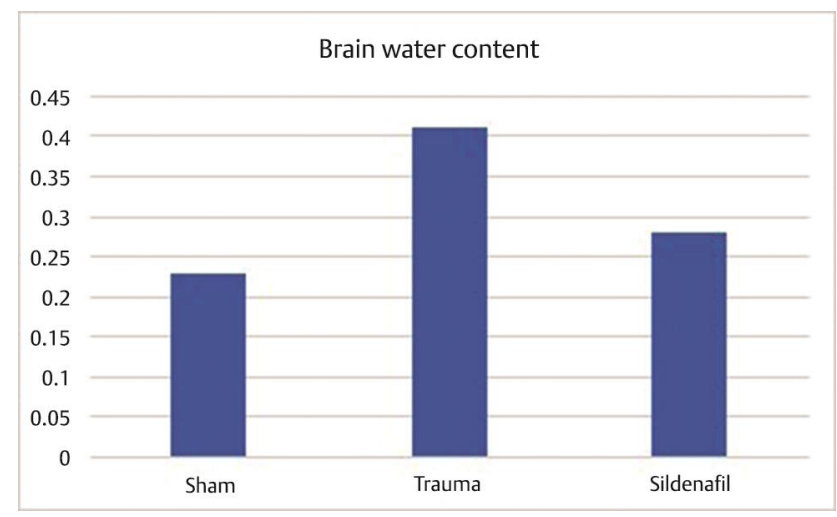

Fig. 1 The water content of the brain was significantly increased in the trauma group when compared with sildenafil-treated trauma group $(p<0.01)$. 


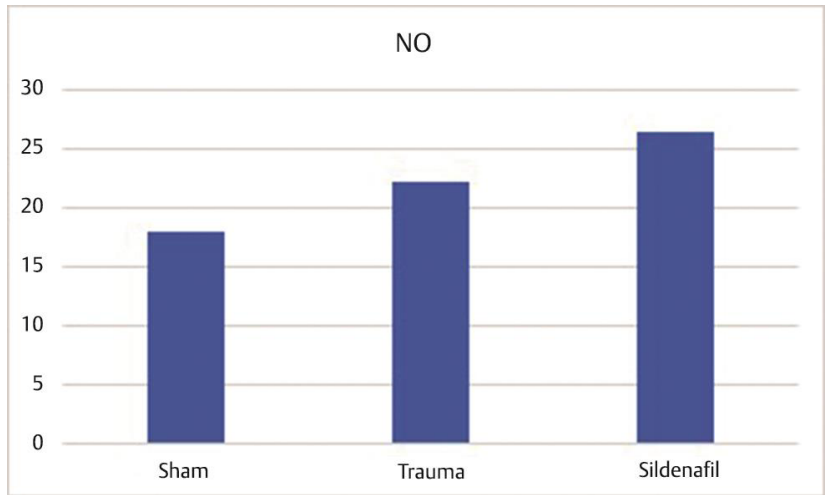

Fig. 2 No level in plasma was significantly increased in the sildenafil group when compared with the trauma group $(26.8 \pm 2, p<0.001)$. The comparison with group 1 and 3 shows that sildenafil was significantly increased the NO level $(p=0.002)$.

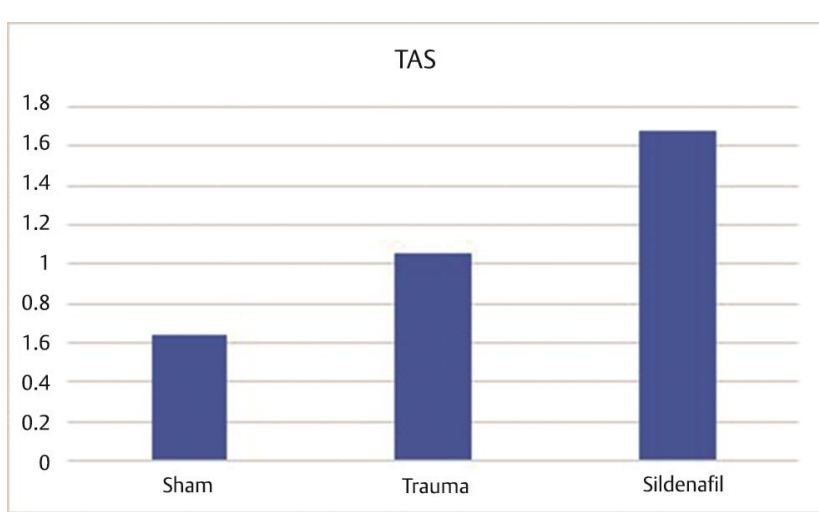

Fig. 3 The results of the total antioxidant status (TAS) level were significantly increased in the sildenafil group when compared with the trauma group $(1.57 \pm 0.2, p=0.02)$.

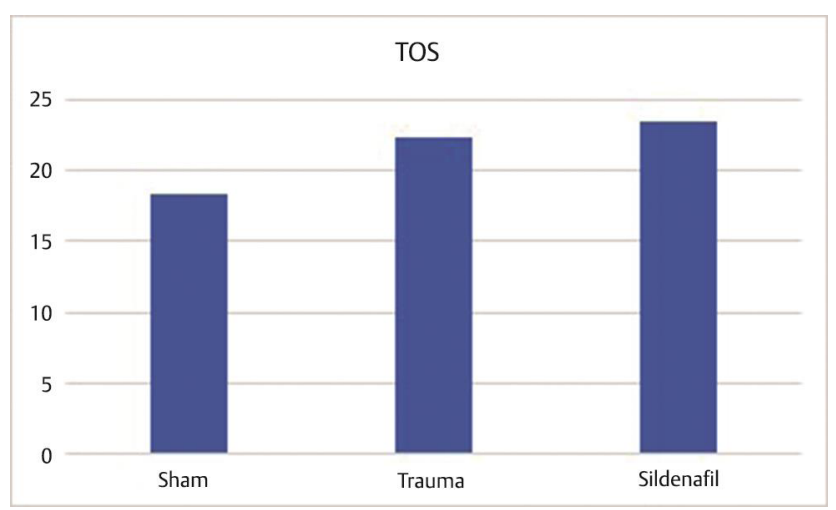

Fig. 4 There was no significant difference between groups 2 and 3 about total oxidant status (TOS) level $(17.79 \pm 3, p=0.225)$.

(-Fig. 6). Brain cortex examinations of the head trauma group revealed the loss of Nissle granules, which characterize neuron damage, the pyknotic status of nuclei, and acidophilic shift of cytoplasm ( $\mathbf{- F i g .} \mathbf{7}$ a, b). The neuron degeneration markers were not seen in the sildenafil-treated trauma group (-Fig. 8).

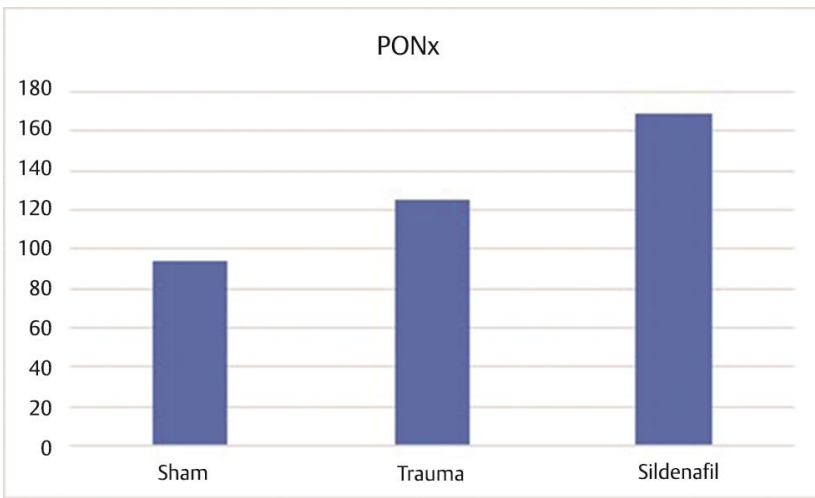

Fig. 5 The results of plasma nitrite/nitrate (PNOx) were significantly increased in the sildenafil group when compared with the trauma group $(115.73 \pm 12, p=0.038)$.

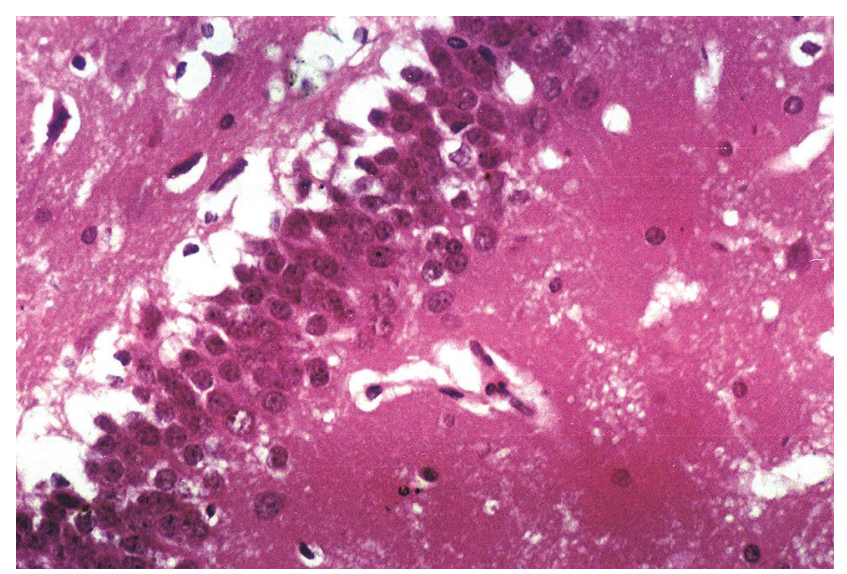

Fig. 6 Sham group: Normal histological contents have been seen in sham group rats (hematoxylin and eosin [H\&E], magnification $\times 160$ ).

\section{Discussion}

Since the definition of the trauma model, defined by Marmarou et al, several studies have been conducted on the pathophysiology of head trauma injuries. ${ }^{15}$ Differentiation of primer injury factors related to trauma from seconder injury factors such as intracranial pressure increase, herniation, brain edema, and brain ischemia in severe head trauma are extremely important for planning treatment.9,16,17 Although many diagnoses and treatment methods are in use in the treatment of patients with an acute head injury, the morbidity and mortality rate are still high. Because of the mechanical effect of the trauma, brain tissue and neurons are damaged. This is called primer injury. A number of complex physiopathological events such as hypoxia, ischemia, increased intracranial pressure, and brain edema, which develop in response to primary trauma in the following minutes, hours, and even days following trauma and increase neuronal damage. This is called a secondary injury. A cascade of events triggered by secondary injury is the work of activation of endogenous cell death pathways. One of the most important factors in the emergence of secondary injury is the 

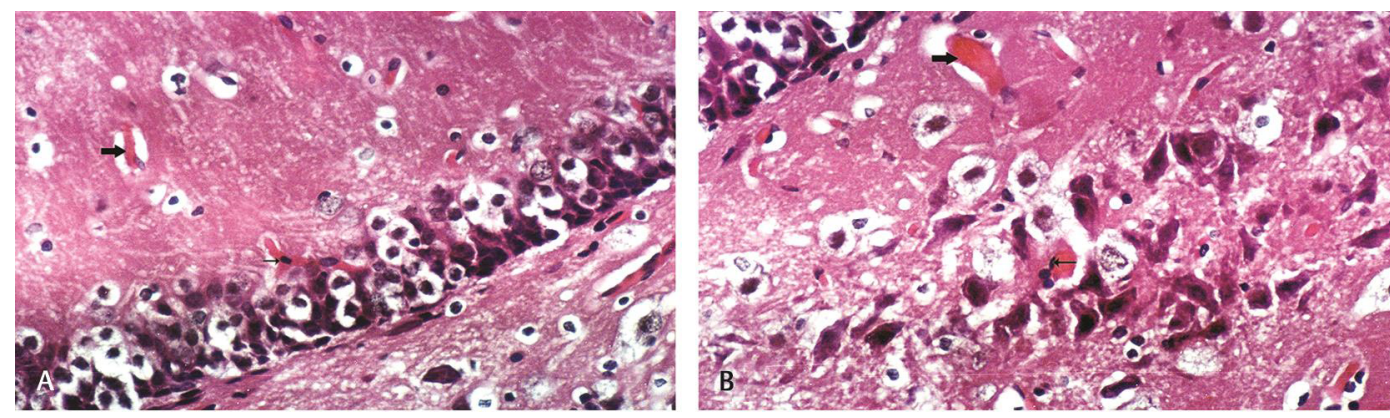

Fig. 7 a, b: Disappearing Nissle granules, the formation of the pyknotic situation in the cell nucleus ( $\square$ ), and acidophilic staining ( $\square$ ) in neuron cells, which describe the neuron degeneration observed in the trauma group (hematoxylin and eosin [H\&E], magnification $\times 160$ ).

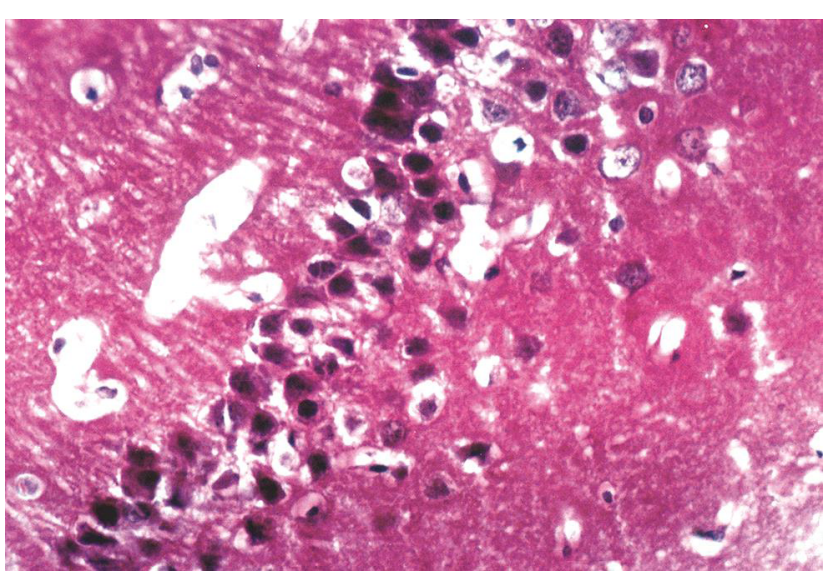

Fig. 8 The neuron degeneration markers were not seen in the sildenafil-treated trauma group.

lack of energy due to ischemia. Ischemia causes a lack of adequate glucose and oxygen uptake to the tissues and indirectly leads to a lack of energy and a decrease in ATP storage. The free radical formation and inflammatory mediator release increase neuron damage. ${ }^{5,6,18}$

NO is an activator of soluble guanylate cyclase (GC) in the target cell and provides CGMP formation from guanosine triphosphate. Phosphodiesterase type 5 (PDE5) is an important enzyme involved in the destruction of cGMP. ${ }^{19,20}$ Sildenafil is a highly selective inhibitor of FDE 5 and leads to increased cGMP in the cell. Experimentally, it showed that NO increases the amount of cGMP in the brain in the stroke studies on rats; thus, accelerating cell regeneration and functional recovery. ${ }^{19}$ Sildenafil reduces oxidative stress by increasing intracellular cGMP. ${ }^{13}$

Studies on Alzheimer's disease animal models have shown us that sildenafil enhances learning and memory. ${ }^{21}$ Despite these studies, the antifatigue and neuroprotective effects of sildenafil are unknown. Brain blood flow studies show that sildenafil decrease transient ischemic attacks in the recovery phase, and they can significantly affect the results of head trauma. $^{5}$

In their study in 2005 and 2006, Whang and Zhang observed that sildenafil can detect the blood-brain barrier in rats, increase the memory and learning capacity, increase neurogenesis, and cause functional recovery of neurological deficits by affecting glutamate NO cGMP pathway. ${ }^{22,23}$ Uthayathas has shown that Parkinson symptoms such as tremor, rigidity, akinesia, and erectile dysfunction, were decreased after sildenafil treatment on Parkinson disease animal model..$^{13}$ In another study, Uthayathas also mentioned that sildenafil showed a direct effect on neurogenesis, memory-enhancing synaptic palsy treatment, and stroke treatment, besides the neuroprotective effect by increasing the blood flow. ${ }^{14}$

In conclusion, the results of our study showed that sildenafil given to rats treated with head trauma decreased oxygen radicals and contributed to tissue healing. However, our results require further clinical research for clinical practice.

\section{Funding}

None.

\section{Ethical Approval}

All applicable international, national, and institutional guidelines for the care and use of animals were followed.

\section{Conflict of Interest \\ None declared.}

\section{References}

1 Corrigan JD, Selassie AW, Orman JA. The epidemiology of traumatic brain injury. J Head Trauma Rehabil 2010;25(2):72-80

2 Bruns J Jr, Hauser WA. The epidemiology of traumatic brain injury: a review. Epilepsia 2003;44(s10):2-10

3 Kraus JF, McArthur DL. Epidemiologic aspects of brain injury. Neurol Clin 1996;14(2):435-450

4 Langlois JA, Rutland-Brown W, Thomas KE. The incidence of traumatic brain injury among children in the United States: differences by race. J Head Trauma Rehabil 2005;20(3):229-238

5 Chesnut RM, Marshall LF, Klauber MR, et al. The role of secondary brain injury in determining outcome from severe head injury. J Trauma 1993;34(2):216-222

6 Ozsüer H, Görgülü A, Kiriş T, Cobanoğlu S. The effects of memantine on lipid peroxidation following closed-head trauma in rats. Neurosurg Rev 2005;28(2):143-147

7 Kayali H, Ozdag MF, Kahraman S, et al. The antioxidant effect of $\beta$-Glucan on oxidative stress status in experimental spinal cord injury in rats. Neurosurg Rev 2005;28(4):298-302

8 Marmarou A, Signoretti S, Fatouros PP, Portella G, Aygok GA, Bullock MR. Predominance of cellular edema in 
traumatic brain swelling in patients with severe head injuries. J Neurosurg 2006;104(5):720-730

9 Hatton J. Pharmacological treatment of traumatic brain injury: a review of agents in development. CNS Drugs 2001;15(7): 553-581

10 Hall ED, Vaishnav RA, Mustafa AG. Antioxidant therapies for traumatic brain injury. Neurotherapeutics 2010;7(1):51-61

11 Corbin JD, Francis SH. Cyclic GMP phosphodiesterase-5: target of sildenafil. J Biol Chem 1999;274(20):13729-13732

12 Chen J, Li Y, Wang L, et al. Therapeutic benefit of intravenous administration of bone marrow stromal cells after cerebral ischemia in rats. Stroke 2001;32(4):1005-1011

13 Uthayathas S, Karuppagounder SS, Tamer SI, et al. Evaluation of neuroprotective and anti-fatigue effects of sildenafil. Life Sci 2007;81(12):988-992

14 Uthayathas S, Karuppagounder SS, Thrash BM, Parameshwaran K, Suppiramaniam V, Dhanasekaran M. Versatile effects of sildenafil: recent pharmacological applications. Pharmacol Rep 2007;59(2):150-163

15 Marmarou A, Foda MA, van den Brink W, Campbell J, Kita H, Demetriadou K. A new model of diffuse brain injury in rats. Part I: Pathophysiology and biomechanics. J Neurosurg 1994;80(2):291-300

16 Unterberg AW, Stover J, Kress B, Kiening KL. Edema and brain trauma. Neuroscience 2004;129(4):1021-1029

17 Cernak I, Chapman SM, Hamlin GP, Vink R. Temporal characterisation of pro- and anti-apoptotic mechanisms following diffuse traumatic brain injury in rats. J Clin Neurosci 2002;9(5):565-572

18 Khan M, Sekhon B, Jatana M, et al. Administration of $\mathrm{N}$-acetylcysteine after focal cerebral ischemia protects brain and reduces inflammation in a rat model of experimental stroke. J Neurosci Res 2004;76(4):519-527

19 Zhang R, Wang Y, Zhang L, et al. Sildenafil (Viagra) induces neurogenesis and promotes functional recovery after stroke in rats. Stroke 2002;33(11):2675-2680

20 Farooq MU, Naravetla B, Moore PW, Majid A, Gupta R, Kassab MY. Role of sildenafil in neurological disorders. Clin Neuropharmacol 2008;31(6):353-362

21 Devan BD, Bowker JL, Duffy KB, et al. Phosphodiesterase inhibition by sildenafil citrate attenuates a maze learning impairment in rats induced by nitric oxide synthase inhibition. Psychopharmacology (Berl) 2006;183(4):439-445

22 Zhang RL, Zhang Z, Zhang L, Wang Y, Zhang C, Chopp M. Delayed treatment with sildenafil enhances neurogenesis and improves functional recovery in aged rats after focal cerebral ischemia. J Neurosci Res 2006;83(7):1213-1219

23 Wang L, Gang Zhang Z, Lan Zhang R, Chopp M. Activation of the PI3-K/Akt pathway mediates cGMP enhanced-neurogenesis in the adult progenitor cells derived from the subventricular zone. J Cereb Blood Flow Metab 2005;25(9):1150-1158 